\title{
CASO OMAR HUMBERTO MALDONADO VARGAS Y OTROS VS. CHILE, A PROPÓSITO DE LA CAUSA "FUERZA AEREA DE CHILE CONTRA BACHELET Y OTROS”*
}

\author{
Christian SuÁrez Crothers \\ Universidad de Talca \\ csuarez@utalca.cl
}

Nuestro país ha sido, hasta ahora, objeto de ocho sentencias condenatorias por violación a los derechos establecidos en la Convención Americana de Derechos Humanos (en adelante, CADH). Durante el año 2005, la Corte Interamericana de Derechos Humanos emitió dos sentencias condenatorias al Estado de Chile (entre las cuales se encuentra la que ahora presentamos), en las que se pronunció sobre violaciones a las garantías judiciales y/o a la protección judicial. En efecto, en el caso Norín Catrimán y otros (dirigentes, miembros y activistas del pueblo indígena mapuche) vs. Chile, la Corte, entre otros aspectos que motivaron una condena, estimó que el Estado había incurrido en una violación de las garantías judiciales del artículo 8.2 (el derecho a la presunción de inocencia), 8.2.f (el derecho de la defensa de interrogar testigos) y 8.2.h (el derecho a recurrir del fallo ante juez o tribunal superior) consagrados en la CADH. Del mismo modo, en el presente caso, la Corte ha estimado que el Estado es responsable por la violación del derecho a las garantías judiciales, reconocido en el artículo 8.1 de la $\mathrm{CADH}$ (en relación con el artículo 1.1 de la misma, junto a los artículos 1, 6 y 8 de la Convención Interamericana para Prevenir y Sancionar la Tortura) y del artículo 25.1 de la misma Convención por violación del derecho a la protección judicial. La Corte ha exigido a Chile la adecuación de su legislación interna para garantizar la investigación ex officio de todos los hechos de tortura que lleguen a su conocimiento y la aplicación por sus tribunales de la regla de exclusión de oficio de pruebas obtenidas mediante tortura, entre otras medidas.

Mientras en Norín Catrimán la Corte, por decisión unánime, no condenó al Estado chileno por incumplir el deber de adoptar disposiciones de derecho interno

* Trabajo recibido el 1 de junio de 2016 y aprobado el 17 de agosto de 2016. 
contenido en el artículo 2 del tratado, en el caso que presentamos, la condena al Estado se extiende a este aspecto, e impone, por lo tanto, al Estado la obligación de adecuar su ordenamiento interno. La Corte IDH declaró que el Estado chileno es responsable de no haber brindado un recurso efectivo para revisar sentencias de condena a personas que fueron torturadas y le ordenó poner a disposición de las víctimas, en el plazo de un año desde la notificación, "un mecanismo que sea efectivo y rápido para revisar y/o anular las sentencias de condena que fueron proferidas en la... causa en su perjuicio"1.

\section{ANTECEDENTES GENERALES}

El caso en comento se inició a raíz de una denuncia efectuada durante el año 2003 por la Corporación de Defensa de los Derechos del Pueblo (Codepu) y la Federación Internacional de Ligas de Derechos Humanos. Los peticionarios solicitaron se hiciera efectiva la responsabilidad internacional del Estado de Chile ante la denegación de justicia en perjuicio de doce personas, que habrían sido torturadas durante la dictadura militar, todas ellas oficiales y suboficiales de la Fuerza Aérea y un miembro del escalafón civil de la misma, derivada de la falta de respuesta estatal frente a los recursos de revisión y reposición interpuestos, indistintamente, el 10 de septiembre de 2001 y el 7 de septiembre de 2002, ante la Corte Suprema. Consideran los peticionarios que el Estado no otorgó un recurso efectivo a las presuntas víctimas para dejar sin efecto un proceso penal que habría tomado en cuenta pruebas obtenidas bajo tortura.

Dichas personas fueron sometidas a consejo de guerra, en conformidad al decreto ley No 3 de 11 de septiembre de 1973, que declaró el estado de sitio en todo el territorio nacional y que otorgó a la junta militar de gobierno la calidad de "general en jefe" de las fuerzas llamadas a operar durante la emergencia ${ }^{2}$. Por su parte, el decreto ley No 5, de 12 de septiembre de ese año y interpretó el artículo 418 del Código Justicia Militar en el sentido de que el estado de sitio decretado debía entenderse como "estado o tiempo de guerra" para los efectos de la aplicación de las normas penales correspondientes. Los consejos de guerra actuaban utilizando un procedimiento breve y sumario, en el que, como registra la sentencia,

1 Párr. 171 del fallo.

2 En efecto, el artículo único del decreto ley disponía que: "Declárese a partir de esta fecha, Estado de Sitio en todo el territorio de la República, asumiendo esta Junta la calidad de General en Jefe de las Fuerzas que operará en la emergencia”. 
la instrucción del fiscal no debía durar más de 48 horas. Concluida la investigación, el caso se elevaba al comandante respectivo acompañando los elementos probatorios y un dictamen en el que, de manera sucinta, se debía indicar a las personas responsables su responsabilidad y las penas que debían imponérsele para el caso de no ser sobreseídas. El comandante en jefe dictaba, luego, la resolución estableciendo los hechos delictivos y convocando al consejo de guerra; consejo que, después de oír la relación del fiscal y la defensa, deliberaba en secreto, apreciaba la prueba y dictaba la sentencia, remitiendo ésta al comandante correspondiente para su aprobación o modificación.

La sentencia registra que, entre los años 1973 y 1975, sólo en la ciudad de Santiago funcionaron alrededor de 46 consejos de guerra que procesaron a 218 personas.

El procedimiento ${ }^{3}$ fue iniciado el 14 de septiembre de 1973 por denuncia del recién nombrado presidente del Banco del Estado, general E.G.B, ante la Fiscalía de Aviación, haciendo alusión genérica al conjunto de reuniones de carácter político que estas personas habrían realizado en las oficinas del ex vicepresidente del banco, con participación de civiles y personal de la Fuerza Aérea y al uso indebido de dineros de dicha institución. Lo anterior derivó en la condena de estas personas, todas las cuales habrían manifestado grados de adhesión al gobierno de la Unidad Popular, por su participación en delitos tales como incumplimiento de deberes militares, conspiración a la sedición, traición y promoción a la sedición (Proceso 1-73). Las presuntas víctimas fueron condenadas a penas privativas de libertad e incluso a penas de muerte (que más tarde fueron conmutadas).

El proceso seguido en su contra habría tenido por objeto lo siguiente. En primer lugar se investigó, como se dijo, a "un grupo formado por personal de la Fuerza Aérea de Chile, dirigentes de los ex $[\mathrm{P}]$ artidos $[\mathrm{S}]$ ocialista, $[\mathrm{C}]$ omunista, $[\mathrm{M}]$ ovimiento de $[\mathrm{A}]$ cción $[\mathrm{P}]$ opular $[\mathrm{U}]$ nitaria (MAPU) y por individuos pertenecientes al [M] ovimiento de [I]zquierda [R] evolucionario (MIR), [que] inició una labor de proselitismo y penetración marxista dentro de las filas de la Institución, ocultando sus verdaderos propósitos bajo el pretexto de defender al gobierno marxista de un presunto golpe de Estado en su contra. Esta acción formaba parte de un objetivo más amplio, [el] cual era efectuar idéntica penetración en las demás ramas de las Fuerzas Armadas y Carabineros, todo ello con el propósito real de destruir su actual estructura y de crear una Fuerza Armada Popular, para el logro definitivo de las metas demostradas, a través de la historia en todos los países en

\footnotetext{
3 Que incluía también al general Bachelet; no derivó en una condena contra éste por haber fallecido antes de la dictación de la sentencia.
} 
que el marxismo ha logrado dominar, esto es, el poder absoluto a base de la dictadura del proletariado". Cfr. Consejo de Guerra, Causa No 1-73 (Primera parte), p. 57 (expediente de prueba, folio 133). En segundo lugar, el objeto de la causa se refirió, según se expresó, a "la responsabilidad de las personas [en] relación con la infiltración en la Unidades de la Fuerza Aérea de Chile, Base Aérea de Quintero, Grupo de Aviación No 7, Escuela de Especialidades, Ala de Mantenimiento, Grupo de Aviación No 10 y Estado Mayor de la Defensa Nacional, por elementos político-extremistas que apoyaban al régimen de Gobierno de la Unidad Popular. Para estos efectos formaron células secretas dentro de las bases, obtuvieron de parte de personal militar infiltrado la entrega de planos, documentos, datos y noticias relativas a la Seguridad de las diversas Unidades Aéreas ya nombradas. Asimismo, se organizaron y planearon la ejecución de planes tendientes a huir de las unidades con armamentos y producir desperfectos mecánicos en aviones institucionales mediante el sabotaje". Cfr. Consejo de Guerra, Causa No 1-73 (Segunda Parte), 27 de enero de 1975, p. 3 (expediente de prueba, folio 384).”

La Comisión IDH elevó el caso a la Corte con fecha 12 de abril de 2014, once años después de presentada la denuncia. La audiencia pública se realizó en Cartagena de Indias en abril de 2015 y el 2 de septiembre de ese año se pronunció la sentencia.

Las presuntas víctimas fueron detenidas, por períodos que llegaron a alcanzar los cinco años, torturadas y sometidas a malos tratos, de acuerdo a un patrón de conducta al que se refiere ampliamente el fallo.

\section{LA ESTRUCTURA DE LA SENTENCIA}

La sentencia fue estructurada, conforme a la manera tradicional de la Corte, en siete acápites: La introducción, en la que se fijó también el objeto de la controversia, el establecimiento de los hechos y, luego, el análisis de fondo del Derecho. Este último análisis recayó, finalmente, en especial sobre: (i) los derechos a las garantías judiciales y a la protección judicial vinculados a la falta de investigación de los hechos de tortura; (ii) el derecho a la protección judicial desde el punto de vista del deber del Estado de adoptar disposiciones de derecho interno ante la ausencia de un recurso de revisión adecuado y efectivo, y (iii) sobre el derecho a la protección de la honra y la dignidad. En este acápite se analizaron los argumentos de las partes y de la Comisión, para luego explayarse la Corte sobre sus propias consideraciones.

Finalmente, por aplicación del artículo 63.1 de la $\mathrm{CADH}$, discurrió sobre las reparaciones, fijando criterios sobre ocho aspectos: parte lesionada, obligación de investigar, medidas de satisfacción, medida de restitución, garantías de no repetición, 
indemnización compensatoria por daño material e inmaterial, costas y gastos y modalidad de cumplimiento de los gastos ordenados y, finalmente, procedió a resolver.

Los hechos denunciados no fueron controvertidos por el Estado, el que durante la audiencia, declaró que "ha reconocido que los peticionarios en esta causa son víctimas de graves violaciones a los derechos humanos cometidas en dictadura, [quienes] fueron sometidos a Consejo de Guerra por su defensa de la Constitución y de la ley, siendo leales al sistema democrático y por ello fueron torturados y condenados por traición a la patria, [y que] esto es algo no discutido en esta causa”. No obstante, la Corte hizo referencia al acervo probatorio con la finalidad de precisar algunos hechos señalados por las partes y la Comisión.

La exposición de los hechos se realiza en los párrafos 19 y siguientes, haciendo alusión a antecedentes referidos al "golpe de Estado y las violaciones de derechos humanos ocurridas durante la dictadura militar", a los procesos ante los consejos de guerra, a los procesamientos de las presuntas víctimas ante dichos Consejos $y$, a las acciones emprendidas por el Estado con posterioridad al retorno a la democracia "en relación con las víctimas de la dictadura".

Posteriormente, en la misma relación de hechos, analiza la solicitud de revisión de las sentencias de condena emitidas en la causa Rol No 1-73 FACH y, finalmente, las investigaciones y procesos por los hechos de tortura en perjuicio de las presuntas víctimas.

\section{EL EJE DEL PROBLEMA}

El eje del problema a resolver radica tanto en establecer si el Estado actuó diligentemente investigando los hechos denunciados de una manera seria, de oficio, exhaustiva e imparcial, como si, a la luz de las pruebas rendidas, ofreció a las víctimas un recurso efectivo y rápido para revisar o anular las condenas pronunciadas sobre personas que fueron objeto de tortura.

\section{El deber del Estado de investigar}

La investigación sobre los hechos de tortura sufridos por las presuntas víctimas se radicó, en dos causas, que la Corte analiza: La causa rol No 1058-2001, iniciada en abril de 2001 por ocho personas que habrían sido torturadas ${ }^{4}$, respecto a la

4 Se refirió a los hechos de tortura sufridos por Belarmino Constanzo Merino, Manuel Osvaldo López Oyanedel, Gustavo Raúl Lastra Saavedra, Víctor Hugo Adriazola Meza, Jaime Arturo Donoso Parra, Mario Antonio Cornejo Barahona, Mario González Rifo y Ernesto Augusto Galaz Guzmán, entre otros. 
cual la Corte concluyó que "el Estado no es responsable por una demora excesiva en iniciar una investigación" (párr. 81), y la rol No 179-2013, también referida a hechos de tortura, esta vez sobre cuatro personas (distintas de las anteriores y entre las que se encuentra don Omar Humberto Maldonado Vargas) ${ }^{5}$, que se inició en agosto de 2013. En este último caso, la Corte estimó "que resulta excesiva la demora en iniciar la investigación" (12 años después de que tuvo noticia de los hechos, al conocer en 2001 el recurso de revisión y nulidad en subsidio interpuesto por la Codepu). Se trata de una causa en que -como indica la Corte, siguiendo lo señalado por los representantes- el Estado estaría "intentando completar lo que quedó pendiente en 2007” (párr. 109), época en la cual (30 de abril de ese año) terminaron las investigaciones con la condena de dos personas por el delito de tormentos o rigor innecesario causando lesiones graves.

En la primera de las causas mencionadas, rol No 1058-2001, fueron sobreseídos temporal y parcialmente en el año 2006, varios querellantes, entre los cuales se encuentran cinco de las presuntas víctimas que, dado el sobreseimiento, no fueron reconocidas como tales víctimas de tortura ${ }^{6}$. Para ellas, el proceso se reabrió en el año 2013, en el marco de la segunda de las causas (rol No 179-2013), lo que está aún siendo investigado. Por esta razón, la Corte Interamericana manifestó que no le corresponde a ella emitir un pronunciamiento sobre esta causa "más allá de las falencias en iniciar esa investigación..." (párr. 89), sin perjuicio de que, como ha indicado en el párr. 159, "debe continuar y concluir, eficazmente, en un plazo razonable y con las debidas diligencias, las investigaciones relacionadas con los hechos de tortura en perjuicio de las víctimas..., con el objetivo de identificar, y en su caso procesar y sancionar a los responsables".

\section{Precisiones en materia de competencia}

La Corte IDH no se pronunció tampoco sobre si Chile se encontraba o no en estado de guerra cuando se produjeron los hechos, ni sobre si la Corte

5 Ivan Rojas Ravanal, Alberto Salustio Bustamante Rojas, Álvaro Yáñez del Villar y Omar Humberto Maldonado Vargas.

6 Víctor Hugo Adriazola Meza, Jaime Arturo Donoso Parra, Mario Antonio Cornejo Barahona, Mario González Rifo y Ernesto Augusto Galaz Guzmán. Según los representantes, la razón para excluirlas de las otras tres fue por carecer de secuelas físicas o psíquicas, siendo que las únicas diferencias "consistían en los resultados de los peritajes médicos, que además no habrían sido conformes con el Protocolo de Estambul”. Párr. 87. 
Suprema carecía o no de competencia para pronunciarse sobre la revisión de la sentencia condenatoria en contra de los lesionados. Sin extenderse demasiado en argumentos sobre su competencia, la Corte asume -sin decirlo- que los hechos materia de la causa son, quizá a la manera que interpretó en Almonacid Arellano, "hechos independientes", producidos con posterioridad a las fechas fijadas por el Estado de Chile para limitar su competencia.

En efecto, la Corte no se va a pronunciar directamente sobre las sentencias dictadas por los consejos de guerra, porque ello sin duda hubiese constituido actuar más allá de la competencia que el Estado le asignó. La Corte sólo revisa, teniendo presente los procesos penales de las causas roles $\mathrm{No}_{\mathrm{s}}$. 1-73 (en virtud de la cual se condenó a las presuntas víctimas), 1058-2001 (del 9o Juzgado del Crimen de Santiago) y 179-2013 (del 34o Juzgado del Crimen de Santiago), si se cumplió, por una parte, con el deber del Estado de investigar los delitos denunciados y si el Estado cuenta, por otra, con un recurso eficaz para revisar y anular las sentencias dictadas contra las víctimas, teniendo especialmente a la vista que las condenas se basaron en probanzas obtenidas mediante tortura.

En un sentido genérico, la Corte no se pronunció sobre la circunstancia de haber existido o no a la fecha de los hechos un patrón de conducta caracterizado como violación masiva de los derechos humanos por parte del Estado, no obstante que lo constata7.

Como lo expresa la misma Corte, al momento de establecer una indemnización de US\$ 30.000 a cada una de las cuatro víctimas de la causa rol No 179, se “...declaró la responsabilidad del Estado de Chile por la violación a los derechos contenidos en el artículo 8.1 de la Convención en relación con 1.1 de la misma y los artículos 1, 6 y 8 de la Convención Interamericana para Prevenir y Sancionar

7 Párr. 33: "Surge en particular que si bien cada una de las presuntas víctimas fue detenida de manera individual, en diferentes lugares y fechas, existía siempre un patrón común: eran detenidas por funcionarios de la FACH armados, eran obligadas a entregar su armamento, eran vendadas y pasaban en algún momento por la Academia de Guerra de la Armada ('AGA') para ser torturadas. Luego de las sesiones de tortura, que podrían demorar semanas, la gran mayoría eran trasladadas a la Academia Politécnica Aeronáutica ('APA') que funcionaba como un centro de acopio de detenidos y que algunas veces desde la APA regresaban a la AGA para ser torturados. Durante la estadía en la AGA y en la APA, los detenidos no podían tener contacto con el exterior, estaban vendados y en posturas forzadas, custodiados por militares armados, además de ser alimentados deficientemente. El proceso de detención y tortura de la mayoría de las presuntas víctimas tuvo lugar principalmente en el período de tiempo comprendido entre septiembre y diciembre de 1973, en el que las víctimas comenzaron a ser trasladados a la Cárcel Pública de Santiago, donde fueron reunidas para iniciar el proceso 1-73 de la FACH que comenzó en abril de 1974 y terminó en ese mismo mes de 1975". Ver también párr. 34. 
la Tortura" (demora excesiva en iniciar la investigación-falta de recurso efectivo para revisar las sentencias de condena) y, al mismo tiempo, por la vulneración en contra de los ocho restantes, a quienes se indemniza con US\$25.000, del derecho a la protección judicial (art 25-1.1 CADH) y del deber de adoptar disposiciones de derecho interno (art. $2 \mathrm{CADH}$ ).

\section{La existencia de recurso eficaz}

frente a la práctica de los recursos de revisión y de nulidad. La regla de exclusión de pruebas obtenidas bajo tortura

El segundo aspecto, que constituye el núcleo central de lo resuelto, se relaciona -en consecuencia- con la declaración de responsabilidad del Estado "por la violación al deber de adoptar disposiciones de derecho interno contenido en el artículo 2 de la Convención, en relación con el artículo 25 del mismo instrumento, por la falta de un recurso que sea adecuado y efectivo para revisar las sentencias de condena de Omar Humberto Maldonado Vargas" y las otras 11 personas que señala el párr. 146.

El Estado alegó que Chile cumple con la obligación de contar con un recurso efectivo para ejercer la regla de exclusión de pruebas obtenidas bajo tortura. La regla de exclusión puede hacerse valer a través de tres procedimientos: la cautela de garantía, el recurso de nulidad y el recurso de revisión, sin perjuicio de que, desde la reforma constitucional de 2005, la Corte Suprema ejerce la superintendencia directiva, correccional y económica sobre los tribunales militares, incluidos los tribunales militares en tiempo de guerra.

La pregunta que se formuló la Corte IDH fue: ¡constituye el recurso de revisión y de nulidad vigente en Chile el recurso eficaz que requiere la CADH? $\mathrm{La}$ respuesta fue negativa, como hemos visto, tomando en consideración para ello,

8 Párr. 182: "De ese modo, la Corte declaró la responsabilidad del Estado de Chile por la violación a los derechos contenidos en el artículo 8.1 de la Convención en relación con 1.1 de la misma y los artículos 1,6 y 8 de la Convención Interamericana para Prevenir y Sancionar la Tortura, en perjuicio de los señores Ivar Onoldo Rojas Ravanal, Alberto Salustio Bustamante Rojas, Alvaro Yánez del Villar, y Omar Humberto Maldonado Vargas, por la demora excesiva para iniciar la investigación, después de más de 12 años de tener noticia de los hechos; por lo que han estado esperando que se haga justicia por los hechos de tortura durante cuatro décadas. Además, el Tribunal declaró la responsabilidad internacional del Estado por la vulneración del derecho a la protección judicial contenido en el artículo 25 de la Convención en relación con los artículos 1.1 y 2, por la falta de un recurso efectivo para la revisión de las sentencias de condena con respecto a esas mismas personas". El subrayado es nuestro. 
entre otros aspectos, los dos recursos presentados por la presuntas víctimas, en 2001 y en 2012.

\section{Recurso de revisión $y$ de nulidad en subsidio de 2001}

En 2001, la Corporación de Promoción y Defensa de los Derechos Humanos (en adelante "Codepu") interpuso un recurso ante la Corte Suprema de Chile solicitando la revisión, y en subsidio la declaración de nulidad y/o la aplicación de las facultades generales para casar de oficio un fallo judicial, en contra de las mencionadas sentencias emitidas en la causa de justicia militar en tiempo de guerra (rol No 1-73).

El artículo 657 del Código de Procedimiento Penal chileno, dispone que "[1]a Corte Suprema puede rever extraordinariamente las sentencias firmes en que se haya condenado a alguien por un crimen o simple delito, para anularlas, en los casos siguientes: '[...] $4^{\circ}$ Cuando, con posterioridad a la sentencia condenatoria, ocurriere o se descubriere algún hecho o apareciere algún documento desconocido durante el proceso, que sean de tal naturaleza que basten para establecer la inocencia del condenado's.

La Corte Suprema de Chile resolvió el 2 de septiembre 2002 que el recurso de revisión con nulidad y casación en subsidio era inadmisible ${ }^{10}$. La razón esgrimida fue que el artículo 70-A numeral 2 del Código de Justicia Militar otorga competencia a la Corte Suprema en materia de jurisdicción militar solamente sobre aquellas sentencias que hayan sido dictadas en tiempo de paz ${ }^{11}$ y que los artículos $6^{\circ}$ y $7^{\circ}$ de la Constitución Política de la República de Chile (que establecen que los órganos del Estado de Chile deben someter su actuar a la normativa interna y que dicho actuar debe estar siempre dentro del marco de su competencia legal) ${ }^{12}$, le llevaban naturalmente a declarar la inadmisibilidad.

\footnotetext{
9 Antiguo Código de Procedimiento Penal de la República de Chile, artículo 657 (expediente de prueba, folios 6102 y 6103).

10 Cfr. Corte Suprema de Chile, Resolución No 13522, causa No 3503/2001, 2 de septiembre de 2002 (expediente de prueba, folio 647).

11 Cfr. Código de Justicia Militar de la República de Chile, artículo 70-A, numeral 2 (expediente de prueba, folio 6127).

12 Cfr. Constitución Política de la República de Chile, 17 de septiembre de 2005, artículos 6º y 70 (expediente de prueba, folio 5835).
} 
Las víctimas presentaron un recurso de reposición el 7 de septiembre de 2002, pero éste también fue rechazado por improcedente ${ }^{13}$.

En efecto, incluso la propia Comisión Rettig ya había constatado en su Informe el criterio de la Corte Suprema ${ }^{14}$.

\section{Reforma constitucional de 2005. Recurso de revisión de 2011}

Pero, años más tarde, en 2005, se reforma la Constitución y se elimina una referencia del artículo 79 que exceptuaba de la superintendencia de la Corte Suprema a los tribunales militares en tiempos de guerra.

Habiéndose modificado la regla constitucional, un grupo de personas distintas a las presuntas víctimas, quienes también habían sido juzgadas y condenadas por consejos de guerra en la causa rol No 1-73, interpusieron, en 2011, un recurso de revisión, el cual fue rechazado por la Corte Suprema, aduciendo que, por no verificarse una ocurrencia, descubrimiento nuevo o aparición de un documento, no podía ser admitido el recurso de revisión, de conformidad con el artículo 657, inciso $4^{\circ}$ del Código de Procedimiento Penal ${ }^{15}$.

Sobre estos aspectos es que recae entonces la sentencia de la Corte Interamericana de derechos humanos.

La Condena a Chile estableció lo siguiente, en su parte resolutiva:

1. "El Estado es responsable por la violación del derecho a las garantías judiciales, reconocido en el artículo 8.1 de la Convención Americana sobre Derechos Humanos, en relación con el artículo 1.1 de la misma y con las obligaciones establecidas en los artículos 1, 6 y 8 de la Convención Interamericana para Prevenir y Sancionar la Tortura, en perjuicio de Ivan Rojas Ravanal, Alberto Salustio Bustamante Rojas, Álvaro Yáñez del Villar, y Omar Humberto Maldonado Vargas, por la excesiva demora en iniciar una investigación, en los términos de los párrafos 76 a 80 de la presente Sentencia.

13 Cfr. Corte Suprema de Chile, Resolución No 19789, causa No 3503/2001, 9 de diciembre de 2002 (expediente de prueba, folio 649).

14 Se dijo: "[p]or sentencias de 13 de noviembre de 1973 y 21 de agosto de 1974, entre otras, la Corte Suprema declaró oficialmente que los Tribunales Militares en tiempo de Guerra no están sometidos a su superintendencia [...]. Al no ejercer estas facultades sobre los Tribunales Militares en [t]iempos de [g]uerra, como habría sido posible entender lo ordenaba la Constitución de 1925, no pudo la Corte Suprema velar por el efectivo cumplimiento por parte de dichos tribunales de las normas que regulan el Procedimiento Penal en Tiempo de Guerra establecidas por el Código de Justicia Militar”.

15 Corte Suprema de Chile, Resolución, 21 de diciembre de 2011 (expediente de prueba, folio 6472). 
2. El Estado es responsable por la violación del derecho a la protección judicial, reconocido en el artículo 25.1 de la Convención Americana sobre Derechos Humanos y al deber de adoptar disposiciones de derecho interno contenido en el artículo 2 de la Convención, en relación con la obligación de respeto y garantía contenida en el artículo 1.1 de la misma, en perjuicio de Omar Humberto Maldonado Vargas, Álvaro Yáñez del Villar, Mario Antonio Cornejo Barahona, Belarmino Constanzo Merino, Manuel Osvaldo López Oyanedel, Ernesto Augusto Galaz Guzmán, Mario González Rifo, Jaime Donoso Parra, Alberto Salustio Bustamante Rojas, Gustavo Raúl Lastra Saavedra, Víctor Hugo Adriazola Meza, e Ivan Rojas Ravanal, por la ausencia de recursos para revisar las sentencias de condena en su contra, en los términos de los párrafos 118 a 142 de la presente Sentencia.

3. El Estado no es responsable por la violación del derecho a la protección de la honra y de la dignidad contenido en el artículo 11 de la Convención en perjuicio de Omar Humberto Maldonado Vargas, Álvaro Yáñez del Villar, Mario Antonio Cornejo Barahona, Belarmino Constanzo Merino, Manuel Osvaldo López Oyanedel, Ernesto Augusto Galaz Guzmán, Mario González Rifo, Jaime Donoso Parra, Alberto Salustio Bustamante Rojas, Gustavo Raúl Lastra Saavedra, Víctor Hugo Adriazola Meza, e Ivan Rojas Ravanal, en los términos de los párrafos 145 a 148 de la presente Sentencia.

\section{Y dispone}

Por unanimidad, que:

4. Esta Sentencia constituye per se una forma de reparación.

5. El Estado debe continuar y concluir, en un plazo razonable, la investigación de los hechos del presente caso, de conformidad con lo señalado en los párrafos 155 y 156 de la presente Sentencia.

6. El Estado debe realizar las publicaciones que se indican en el párrafo 162 del presente Fallo, dentro del plazo de un año contado desde la notificación de la presente Sentencia.

7. El Estado debe, dentro del plazo de un año contado desde la notificación de la presente Sentencia, realizar un acto público de reconocimiento de responsabilidad internacional, de conformidad con lo señalado en el párrafo 160 de la presente Sentencia.

8. El Estado debe, dentro del plazo de un año contado desde la notificación de la presente Sentencia, develar una placa con la inscripción de los nombres de las 
víctimas del presente caso, de conformidad con lo señalado en el párrafo 164de la presente Sentencia.

9. El Estado debe poner a disposición de las víctimas del presente caso, dentro del plazo de un año contado desde la notificación de la presente Sentencia, un mecanismo que sea efectivo y rápido para revisar y anular las sentencias de condena que fueron dictadas en la referida causa en su perjuicio, de conformidad con lo señalado en el párrafo 167 de la presente Sentencia. Ese mecanismo deber ser puesto a disposición de las demás personas que fueron condenadas por los Consejos de Guerra durante la dictadura militar chilena de conformidad con lo señalado en el párrafo 170 de la presente Sentencia.

10. El Estado debe pagar dentro del plazo de un año, contado a partir de la notificación de la presente Sentencia, la cantidad fijada por concepto de daño inmaterial ocasionado a Omar Humberto Maldonado Vargas, Álvaro Yáñez del Villar, Mario Antonio Cornejo Barahona, Belarmino Constanzo Merino, Manuel Osvaldo López Oyanedel, Ernesto Augusto Galaz Guzmán, Mario González Rifo, Jaime Donoso Parra, Alberto Salustio Bustamante Rojas, Gustavo Raúl Lastra Saavedra, Víctor Hugo Adriazola Meza, e Ivan Rojas Ravanal, de conformidad con lo señalado en los párrafos 178 y 179 de la presente Sentencia.

11. El Estado debe pagar dentro del plazo de un año, contado a partir de la notificación de la presente Sentencia, las cantidades fijadas en el párrafo 185 de la presente Sentencia, por concepto de reintegro de costas y gastos, en los términos de los párrafos 180 a 185 de la misma”.

12. El Estado debe rendir al Tribunal un informe sobre las medidas adoptadas para cumplir con la misma, dentro del plazo de un año, contado a partir de la notificación de la presente Sentencia.

13. La Corte supervisará el cumplimiento íntegro de esta Sentencia, en ejercicio de sus atribuciones y en cumplimiento de sus deberes conforme a la Convención Americana sobre Derechos Humanos, y dará por concluido el presente caso una vez que el Estado haya dado cabal cumplimiento a lo dispuesto en la misma”.

\section{CONCLUSIONES}

La sentencia coloca nuevamente al Estado de Chile frente a la obligación de adecuar su ordenamiento interno a los estándares de la CADH. Esa obligación es extensible al Estado en su conjunto y, por tanto, recae sobre sus distintos órganos. La Corte IDH ha declarado que el Estado lesionó el derecho a la garantía judicial 
por el retardo excesivo de la investigación en uno de los casos mencionados, pero también la garantía de protección judicial, dada la inexistencia de un recurso eficaz para revisar o anular sentencias condenatorias.

Respecto de la investigación que sigue su curso, le fija reglas ${ }^{16}$ a las que debe ajustarse para no incumplir el estándar exigido por la Corte interamericana ${ }^{17}$. De particular relevancia es el párrafo 156 de la sentencia:

“156. En particular, para tales efectos, el Estado deberá: a) asegurar el pleno acceso y capacidad de actuar de las víctimas y sus familiares en todas las etapas de estas investigaciones, de acuerdo con la ley interna y las normas de la Convención Americana; b) por tratarse de una violación grave de derechos humanos y en consideración de las particularidades y el contexto en que ocurrieron los hechos, el Estado debe abstenerse de recurrir a figuras como la amnistía en beneficio de los autores, así como ninguna otra disposición análoga, la prescripción, irretroactividad de la ley penal, cosa juzgada, ne bis in idem o cualquier eximente similar de responsabilidad, para

16 Ver párr. 75: "La Corte ha considerado que el Estado está en la obligación de proveer recursos judiciales efectivos a las personas que aleguen ser víctimas de violaciones de derechos humanos (artículo 25 de la Convención), recursos que deben ser sustanciados de conformidad con las reglas del debido proceso legal (artículo 8.1 de la Convención), todo ello dentro de la obligación general, a cargo de los mismos Estados, de garantizar el libre y pleno ejercicio de los derechos reconocidos por la Convención a toda persona que se encuentre bajo su jurisdicción (artículo 1.1 de la Convención). En relación con lo anterior, se 'debe asegurar, en tiempo razonable, el derecho de las presuntas víctimas o sus familiares a que se haga todo lo necesario para conocer la verdad de lo sucedido y se sancione a los eventuales responsables'. El deber mencionado se ve especificado y complementado por la Convención Interamericana para Prevenir y Sancionar que, de conformidad a sus artículos 1, 6 y 8, impone los deberes de 'realizar una investigación' y 'sancionar', en relación con actos de tortura. De modo consecuente, existe un deber estatal de investigar los hechos, que es una obligación de medio y no de resultado, pero que debe ser asumida por los Estados como un deber jurídico propio y no como una simple formalidad condenada de antemano a ser infructuosa, o como una mera gestión de intereses particulares, que dependa de la iniciativa procesal de las víctimas o sus familiares, o de la aportación privada de elementos probatorios".

17 155. "La Corte estableció en la presente Sentencia que el Estado había violado el artículo 8.1 de la Convención, en relación con el artículo 1.1 de la misma, y con las obligaciones establecidas en los artículos 1, 6 y 8 de la Convención Interamericana para la Prevención y Sanción de la Tortura, en tanto que resultó excesiva la demora del Estado en iniciar la investigación de los hechos ocurridos a cuatro de las víctimas del caso, a saber los señores Ivar Onoldo Rojas Ravanal, Alberto Salustio Bustamante Rojas, Álvaro Yánez del Villar, y Omar Humberto Maldonado Vargas (supra párr. 80). Sin perjuicio de ello, en el año 2013, el Estado inició mediante querella de parte las investigaciones por los hechos de tortura en perjuicio de las 12 víctimas del presente caso, la cual se encuentra todavía en curso (supra párr. 69). Como consecuencia de lo anterior, este Tribunal dispone que el Estado debe continuar y concluir, eficazmente, en un plazo razonable y con las debidas diligencias, las investigaciones relacionadas con los hechos de tortura en perjuicio de las víctimas de este caso, con el objetivo de identificar, y en su caso procesar y sancionar a los responsables". 
excusarse de esta obligación; c) garantizar que las investigaciones y procesos por los hechos del presente caso se mantengan, en todo momento, bajo conocimiento de la jurisdicción ordinaria, y d) divulgar públicamente los resultados de los procesos para que la sociedad chilena conozca la determinación judicial de los hechos objeto del presente caso. Del mismo modo el Estado deberá divulgar el resultado de una eventual revisión de las condenas de las 12 víctimas de este caso en un medio de difusión interno de las Fuerzas Armadas de Chile con la finalidad que el mismo sea conocido por todos sus miembros".

Como ha venido ocurriendo últimamente, la Corte no se pronuncia sobre la alegacion de la Comisión IDH de haber incumplido el Estado su "obligación" de realizar un control de convencionalidad. Tampoco invita, como otras veces lo ha hecho (sentencia Almonacid), a que las autoridades del Estado realicen tal control. Simplemente, y de manera correcta a nuestro juicio, la Corte se limitó a resolver el conflicto identificando dos lesiones a normas de derechos humanos contenidas en la Convención, incorporando en su razonamiento, y asumiendo, que el Estado infringió la Convención Interamericana para Prevenir y Sancionar la Tortura. No obstante, como vemos, la Corte IDH fija un parámetro estricto, al señalar (párr.156) que "el Estado debe abstenerse de recurrir a figuras como la amnistía en beneficio de los autores, asi como ninguna otra disposición análoga, la prescripción, irretroactividad de la ley penal, cosa juzgada, ne bis in idem o cualquier eximente similar de responsabilidad".

Fija la Corte un breve plazo, un año desde la notificación de la sentencia, para que el Estado le brinde a las víctimas "un mecanismo que sea efectivo y rápido para revisar y anular las sentencias de condena" que fueron dictadas en su contra, entre otras medidas de reparación.

En atención a que Chile no cuenta, lamentablemente, con un procedimiento normado para cumplir las sentencias dictadas por tribunales internacionales y funciona a través de prácticas que involucran la certificación de la sentencia por parte del Subsecretario de Relaciones Exteriores y la comunicación de la misma a los ministerios de Justicia y Hacienda, para los fines que sean pertinentes, el presidente del Consejo de Defensa del Estado, en su calidad de representante judicial del Estado de Chile, requirió al Ministerio Público Judicial para que interpusiera un recurso de revisión de las sentencias dictadas por los Tribunales de Justicia Militar en Tiempo de Guerra, en la causa caratulada 'Fuerza Aérea de Chile contra Bachelet y otros', (...) con el objeto de que dichas sentencias sean anuladas, por existir antecedentes que acreditan de manera indubitada que ellas se basaron en declaraciones obtenidas mediante torturas. 
En el mes de mayo de 2016, el Fiscal Judicial de la Corte Suprema, invocando la petición del Consejo, interpuso en la causa recurso de revisión para tales efectos, el que se encuentra pendiente ante el mismo Tribunal ${ }^{18}$.

La sentencia de la Corte IDH tiene interés también porque, a modo de obiter, se pronunció sobre "los obstáculos que pudo significar la negativa por parte de la Comisión Valech de remitir los antecedentes al Juzgado 90"19. Para determinar si la restricción de acceso a la información contenida en el archivo de la comisión Valech era contraria a la Convención Americana, la Corte efectuó un análisis sobre la proporcionalidad del artículo 15 de la ley No 19.992 de 2004 (párrafos 91 y ss.), buscando establecer si dicha restricción i) es legal, ii) cumple con una finalidad legítima, iii) es necesaria y iv) es estrictamente proporcional. La Corte concluyó $^{20}$, finalmente, sobre el carácter proporcional de la medida.

Por último, la Corte desestimó que se hubiese lesionado el derecho al honor de las víctimas y sus familias:

"145. Esta Corte constata que los representantes alegaron que las acciones y omisiones del Estado que supuestamente dieron lugar a violaciones de los derechos contenidos en el artículo 25 de la Convención, en relación con los artículos 1.1 y 2 de la misma, también habrían conllevado la alegada violación del artículo 11. En particular, los alegatos sostienen que el Estado es responsable por la violación a ese derecho por tres motivos diferentes: 1) por haber emitido sentencias de condena sin que se respetaran las debidas garantías y con la finalidad de obtener 'una venganza política'; 2) por no haber anulado por medio de algún mecanismo esas sentencias, y 3) por la inexistencia de un mecanismo o recurso efectivo para revisar juicios con infracción al debido proceso y para ejercer la regla de exclusión.

18 Fuerza Aérea de Chile contra Bachelet y otros, Recurso de Revisión, Corte Suprema, Rol No 27543-2016.

19 Párr. 88 de la sentencia: “... el Juzgado 9 que intervino en la causa 1058-2001 solicitó información a la Comisión Valech referida a los antecedentes de varias personas que habían sido incluidas en el listado de víctimas de la misma (supra párr. 55) y que el 3 de enero de 2005 esa solicitud de información le fue negada por la Comisión Valech, invocando el artículo 15 de la ley No 19.992 de 17 de diciembre de 2004 que establece la reserva de los documentos, testimonios y antecedentes aportados por las víctimas ante la Comisión Nacional sobre Prisión Política y Tortura. El oficio referido de la Comisión Valech reitera lo enunciado en el inciso $3^{\circ}$ de dicho artículo 15 , el cual indica expresamente que mientras rija el secreto previsto en ese artículo, "ninguna persona, grupo de personas, autoridad o magistratura tendrá acceso a lo señalado [...], sin perjuicio del derecho personal que asiste a los titulares de los documentos, informes, declaraciones y testimonios incluidos en ellos, para darlos a conocer o proporcionarlos a terceros por voluntad propia”.

20 Párr. 99, que “... En consecuencia, el Tribunal encuentra que la restricción de acceso a la información dispuesta por el artículo 15 de la ley No 19.992 es proporcional puesto que el sacrificio inherente a la restricción no resulta exagerado o desmedido frente a las ventajas que se obtienen mediante tal restricción y el cumplimiento de la finalidad perseguida". 
146. Con respecto al primer punto, la Corte recuerda que carece de competencia ratione temporis para efectuar un análisis de las sentencias emitidas en el marco del proceso 1-73, por lo que tampoco es posible sacar conclusiones relativas a la finalidad de las condenas y una eventual utilización de esos procesos judiciales para violar el derecho a la honra y dignidad de las presuntas víctimas. Como ya fuera señalado, en el capitulo de hechos (supra párr. 17), se mencionaron las sentencias de condenas en el proceso 1-73 unicamente como antecedentes para contextualizar los hechos del presente caso, pero no con la finalidad de concluir que existian violaciones a las garantías judiciales en el marco de esos procesos, lo que queda fuera de la competencia temporal de la Corte y tampoco fue alegado como objeto del caso por las partes ni la Comisión.

147. Asimismo, este Tribunal nota que los representantes no indicaron de qué manera la falta de anulación de las sentencias de condena del proceso 1-73 o la alegada inexistencia de un recurso de revisión para ese tipo de condenas, se habría traducido en violaciones de derechos especificas diferentes a las ya establecidas en los demás capitulos. Ya fue analizada la falta de un recurso efectivo contra las sentencias condenatorias del proceso 1-73 en el capitulo sobre el artículo 25 de la Convención. En consecuencia, en el presente caso la Corte se remite a lo resuelto en esta misma Sentencia en relación con el derecho a la protección judicial en perjuicio de las victimas, por lo que no se pronunciará respecto de la alegada violación del derecho a la honra y dignidad.

148. Sin perjuicio de lo anterior, las afectaciones a las víctimas de la violación al derecho a la protección judicial, así como las pruebas de ello, se tendrán en cuenta en el capitulo sobre reparaciones respecto al daño inmaterial".

Para concluir, llama la atención que el Estado chileno -mas allá de esta sentencia- mantenga las reservas introducidas (en los años 80) a la competencia de los órganos de la Convención sobre la Tortura de Naciones Unidas (Corte de La Haya) y de la Convención Interamericana para la Prevención y Sanción de la Tortura. 